\title{
Young People's Entry into Higher Education: quantifying influential factors
}

\author{
VERNON GAYLE, DAMON BERRIDGE \& RICHARD DAVIES
}

\begin{abstract}
The government has recently raised the issue of differential rates of participation in higher education. The overall aim of this paper is to present an example of the kind of detailed research necessary to identify factors associated with low rates of participation in higher education by some groups of young people. A number of studies have suggested that in addition to educational attainment, issues such as social class, gender and parental education also influence a young person's likelihood of entering higher education. In this paper we undertake exploratory analysis of a series of nationally representative data and through statistical modelling we then identify the factors that influence a young person's chances of entry into higher education and participating on a degree level course. Through sample enumeration, an innovative statistical methodology, we were then able to quantify the substantive effects of these factors. We found that net of educational attainment a number of factors (e.g. gender and social background variables) influence the likelihood of a young person entering higher education and participating on a degree level course. In addition our analysis highlights the interwoven effects of parental education and schooling and we discuss the complex nature of the effects of ethnicity.
\end{abstract}

\section{INTRODUCTION}

The National Committee of Enquiry into Higher Education (Dearing, 1997) highlighted the existence of unequal rates of participation in higher education by some groups within society. The recent Green Paper The Learning Age-A Renaissance for a New Britain, directly addresses the issue of opening up access to higher education. The government states that their priority is to reach out and include those from groups that have been under-represented in higher education. These include young people from semi-skilled or unskilled family backgrounds and certain ethnic minorities.

The analysis of differential rates of access to higher education has a long history (see for example Rudd, 1976, 1987a \& 1987b; Halsey et al., 1980; Moore, 1983; Royal Statistical Society, 1985; Redpath \& Harvey, 1987; Burnhill et al., 1988 \& 1990; Blackburn \& Jarman, 1993; Cheng \& Heath, 1993; Eggerton \& Halsey, 1993; Halsey, 1993; Modood, 1993; Paterson, 1993 \& 1997; Batey \& Brown, 1997; Metcalf, 1997; Parry, 1997; Savage \& Egerton, 1997; Raab, 1998). Anyone surveying the literature in this area will become aware of its confused nature. This is partly due to the different focus of these research projects. Some studies are primarily concerned with the analysis of the education system, whereas others focus on young people and higher education, 
upon class analysis and social mobility, or address issues of planning and social policy. Whilst the existing studies document useful results, the disparate nature of the sources of data which are analysed and the methodologies that are employed mean that comparisons are problematic.

Overall, the literature on access to higher education sends the message that there is social inequality. Breen and Goldthorpe (1997) argue that the wealth of sociological evidence seems to suggest that a series of empirical generalisations can readily be made and constitute explananda. Young people of less advantaged social backgrounds have not increased their levels of participation in more ambitious educational options, thus closing the gap with their more advantaged counterparts.

This paper is timely because the Government has put the subject of inequality of access back on the agenda and have suggested that there is a need to identify the factors that lead some young people not to enter higher education (see especially Section 4.31 of the Green Paper). In this paper we report the initial findings of a research project on young people's routes to higher education. The primary aim of this paper is to present an example of the kind of detailed research which we believe is required to identify the factors which influence young people's entry into higher education and are associated with low rates of participation by various social groups.

In this paper we undertake analysis of a set of nationally representative data (The Youth Cohort Study of England and Wales). Our approach has been to undertake an exploratory statistical analysis in order to identify a range of factors that influence young people's entry into higher education and participation on degree level programmes of study. Our primary research question is, 'net of attainment, do external influences such as family's social class, parental education, gender and ethnicity influence a young person's chance of studying for a degree?'

An integral aspect of the paper is that we bring to bear a distinct statistical methodology, namely sample enumeration. As well as identifying the 'statistically' significant factors that influence entry to higher education it will be possible to quantify their 'substantive' significance. Methodologically, this represents a substantial departure from the limits of the conventional interpretation of statistical models within sociology. Following from this, adopting a sample enumeration methodology allows us to extend the substantive sociological analysis of this issue.

\section{DATA}

The Youth Cohort Study of England and Wales (YCS) is a major programme of longitudinal research designed to monitor the behaviour and decisions of representative samples of young people aged 16 to 19 as they reach minimum school leaving age and either stay on in education or enter the labour market. The survey collects information on the young people's experiences of education, training and work as well as information on their aspirations, their family and their personal circumstances. Therefore the YCS contains relevant variables for the analysis here. Cohort members are contacted by post three times, at yearly intervals, when they are 16-17, 17-18 and 18-19, and in the case of Cohort III again at age 23. In this paper we undertake analysis of Cohort III data. The young people in this cohort were born in 1969 and 1970. This cohort is of particular interest as it coincides with the expansion in British higher education in the later 1980s. In this analysis our outcome variable is whether or not the young person was studying for a degree (in sweep 3). 


\section{RESULTS}

We tested for a wide range of effects including individual, family background and school factors (see Table I). Academic attainment is central to young people's entry to degree level higher education. The analysis indicates that, after controlling for individual attainment, family's occupational social class, gender, parental education, ethnicity, home ownership, schooling, family size and marital status are significant main effects. In the next stage of the analysis we tested for two-way (see Table II) and three-way interaction effects (see Table III). In addition to the main effects there was a significant interaction between parental education and schooling. The model of best fit is reported in Table IV.

TABLE I. Studying for a degree significant variables

\begin{tabular}{ll}
\hline Variable & Significant \\
\hline Attainment (examination grades) & $\checkmark$ \\
Family's occupational social class (Registrar General's Classification) [1] & $\checkmark$ \\
Gender & $\checkmark$ \\
Parental education (graduates) & $\checkmark$ \\
Ethnicity & $\mathrm{X}$ \\
Young person of Indian origin & $\checkmark$ \\
Father's occupational status [2] & $\mathrm{X}$ \\
Mother's occupational status [2] & $\mathrm{X}$ \\
Father unemployed & $\mathrm{X}$ \\
Mother unemployed & $\mathrm{X}$ \\
Father self employed & $\mathrm{X}$ \\
Mother self employed & $\mathrm{X}$ \\
Parents own home & $\checkmark$ \\
Attended independent school (Year 11) & $\checkmark$ \\
Lone parent family & $\mathrm{X}$ \\
Family formation [3] & $\mathrm{X}$ \\
Marital status age 17-18 & $\mathrm{X}$ \\
Marital status age 19 & $\sqrt{ }$ \\
Young Person has a Disability & $\mathrm{X}$ \\
Geographic Region [4] & $\mathrm{X}$ \\
Number of siblings & $\checkmark$ \\
\hline
\end{tabular}

$\checkmark=$ Significant $(p \leq 0.05) \quad$ X Not Significant $(p>0.05)$

[1] The development of a combined family's occupational social class measure was informed by earlier sociological work (see Erikson, 1984). Both mother's and father's occupational social class (Registrar General's Classification) were fitted to the model. The results of these two measures were roughly equivalent, although many young people had mothers who were not in paid employment. We examined both parents' occupational social class position and taking the higher Registrar General's social class as the measure of family's occupational social class constructed a combined measure of family's social class. Substantively, a measure of social class for the family unit is more appropriate than a measure based on the occupation of only one parent, given contemporary family formations.

[2] Occupational status was measured using the following categories:- Full-Time Job; Part-Time Job; Unemployed; Retired; Full-Time Housework; Other; Unsure; Deceased.

[3] Family formation was measured using the following categories:- Living with Both Parents; Mother Only; Father Only; Neither Parent; Spouse or Partner (Age 16-17); With Other Relatives.

[4] The YCS crudely classifies young people into the following regions:- South East; Yorks \& Humber; North West; East Midlands; West Midlands; East Anglia; Greater London. 


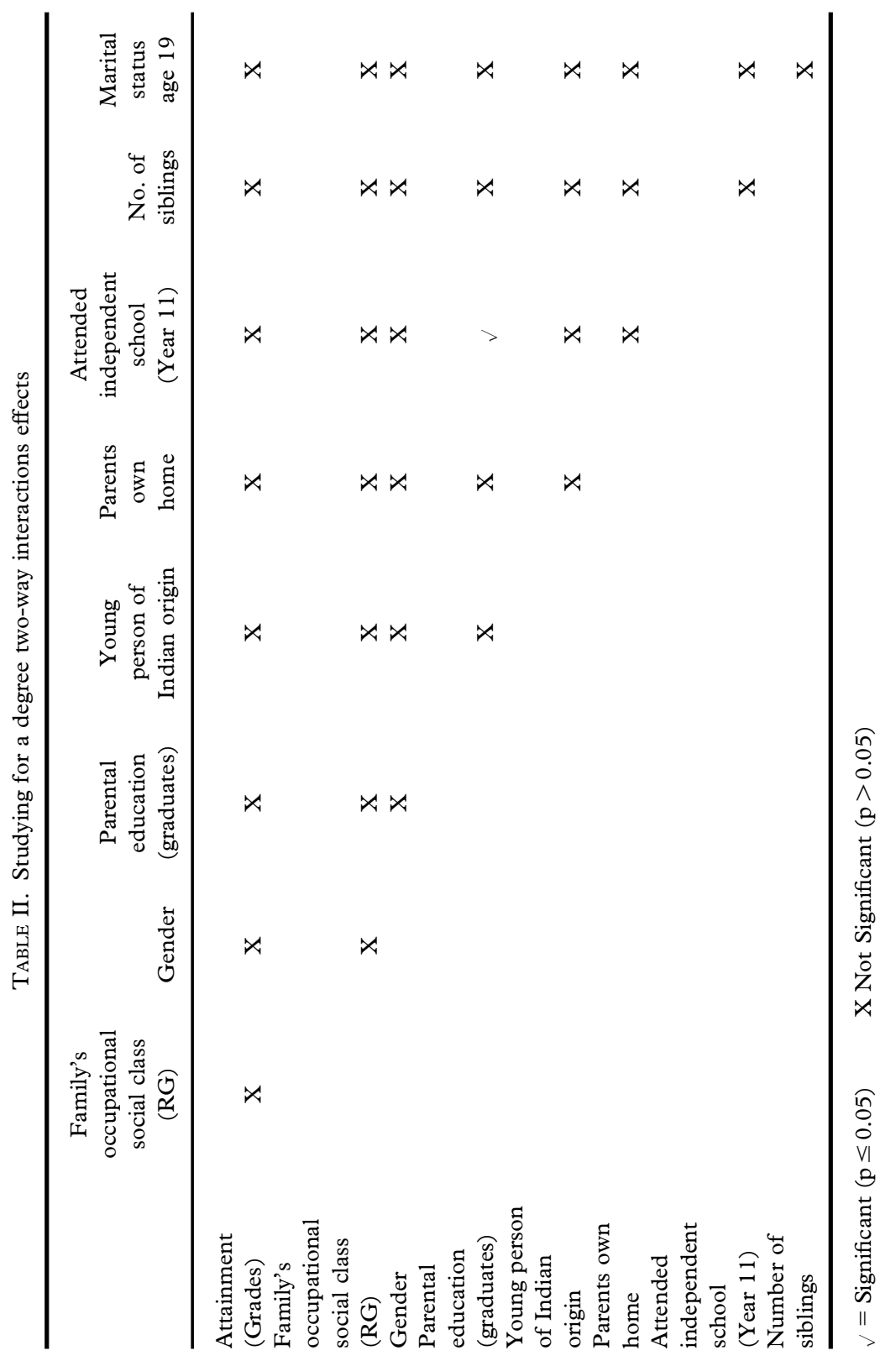


TABLE III. Studying for a degree three-way interactions

\begin{tabular}{lc}
\hline & $\begin{array}{c}\text { Parental education (graduates) } \\
\text { Attended independent school (Year 11) }\end{array}$ \\
\hline Attainment (grades) & $\mathrm{X}$ \\
Family's occupational social class (RG) & $\mathrm{X}$ \\
Gender & $\mathrm{X}$ \\
Young person of Indian origin & $\mathrm{X}$ \\
Parents own home & $\mathrm{X}$ \\
Attended independent school (Year 11) & $\mathrm{X}$ \\
Number of siblings & $\mathrm{X}$ \\
\hline
\end{tabular}

$\checkmark=$ Significant $(p \leq 0.05) \quad X$ Not Significant $(p>0.05)$

TABLE IV. Studying for a degree model of best fit (logistic regression)

\begin{tabular}{|c|c|c|c|c|c|c|}
\hline Variable & $\begin{array}{l}\text { Change in } \\
\text { deviance }\end{array}$ & $\mathrm{df}$ & Estimate & S.E. & $\begin{array}{l}\text { Odds } \\
\text { ratio }\end{array}$ & $\begin{array}{l}\text { Cases in } \\
\text { category (\%) }\end{array}$ \\
\hline Constant & & & 1.32 & 0.267 & & \\
\hline Attainment & 2154 & 4 & & & & \\
\hline Social class & 89.38 & 4 & & & & \\
\hline Intermediate & & & -0.2339 & 0.108 & 0.79 & 32 \\
\hline Skilled non-manual & & & -0.3993 & 0.127 & 0.67 & 24 \\
\hline Skilled manual & & & -0.5707 & 0.134 & 0.56 & 28 \\
\hline Semi-skilled & & & -0.8629 & 0.556 & 0.42 & 5 \\
\hline Unskilled & & & Aliased & - & - & 2 \\
\hline Gender & 34.99 & 1 & & & & \\
\hline Females & & & -0.3832 & 0.071 & 0.68 & 54 \\
\hline Parental education & 37.85 & 1 & & & & \\
\hline Non-graduate parents & & & -0.06510 & 0.1779 & 0.93 & 83 \\
\hline $\begin{array}{l}\text { Ethnicity } \\
\text { (Indian origin) }\end{array}$ & 12.88 & 1 & & & & \\
\hline Not of Indian origin & & & -0.7969 & 0.2321 & 0.45 & 98 \\
\hline Home ownership & 23.29 & 1 & & & & \\
\hline Parent's don't own home & & & -0.5180 & 0.1287 & 0.59 & 21 \\
\hline Independent school & 30.57 & 1 & & & & \\
\hline Attended state school & & & -0.2484 & 0.1498 & 0.78 & 93 \\
\hline $\begin{array}{l}\text { Number of siblings } \\
\text { (mean }=2.8 ; \text { median }=2.0 ; \\
\text { s.dev. }=3.14)\end{array}$ & 13.53 & 1 & -0.05072 & 0.0146 & 0.95 & \\
\hline Marital status (Age 19) & 15.79 & 1 & & & & \\
\hline Married & & & -1.526 & 0.4725 & 0.21 & 4 \\
\hline Interaction effect & 6.66 & 1 & & & & \\
\hline $\begin{array}{l}\text { Attended state school \& } \\
\text { non graduate parents }\end{array}$ & & & -0.5074 & 0.1962 & 0.60 & 79 \\
\hline
\end{tabular}

$\mathrm{n}=8573$

\section{Sample Enumeration}

In this section we outline the principles of sample enumeration as a method of interpreting the results of logistic regression models. In the next section we will employ sample enumeration to interpret the results of the logistic regression model presented 
TABLE V. Studying for a degree by social class (two highest occupational social classes)

\begin{tabular}{lcc}
\hline & Professional & Intermediate \\
\hline Studying for a degree & 240 & 577 \\
Not studying for a degree & 484 & 2170 \\
\hline
\end{tabular}

above (Table IV). We will illustrate that this procedure allows us to quantify the 'substantive' significance of the 'statistically' significant factors in the model.

Our principal research question is 'net of attainment, do external influences such as family's social class, parental education, gender and ethnicity influence a young person's chance of studying for a degree?' For the moment we will concentrate on family's occupational social class. Put simply, we are interested in the direct effects of this variable.

A standard approach would be to use odds ratios. Table $\mathrm{V}$ reports the numbers of young people who were studying for a degree in the highest two occupational social classes. The odds of studying for a degree, as opposed to not studying for a degree, for a young person in the professional social class are $0.49(=240 / 484)$. The odds of studying for a degree, as opposed to not studying for a degree, for a young person in the intermediate social class are $0.26(=577 / 2170)$. Therefore the odds ratio of studying for a degree for young people from the intermediate social class compared with young people from the professional social class is given by $0.53(=0.26 / 0.49)$. Conventionally, this may be interpreted as a measure of association between the two variables in a cross-tabulation analysis.

This cross-tabulation is based upon observational data. Therefore the question arises as to the extent that the observed association is due to a direct, 'causal' relationship and the extent to which it is a spurious relationship attributable to failure to control for other variables. The next logical step in the analysis process would be to fit a statistical model including appropriate control variables as we have done above.

The logistic regression model (see Table IV) includes a range of explanatory variables that from a substantive point of view might be important. The family's occupational social class effect is still significant $(p<0.01)$ and is not eliminated by the inclusion of the other variables. A synoptic examination of the parameter estimates indicates an ordinal structure to the occupational social class effect. This is consistent with substantive sociological theories on the effects of family's occupational social class on educational participation. These results do not, however, immediately address the issue of how much of the observed relationship is explained by the other variables and how much is explained by the family's occupational social class.

The corresponding odds ratio for an explanatory variable are given by $\hat{\lambda}=\exp (\hat{\beta})$, where $\hat{\beta}$ is the estimated parameter value included in Table IV. The estimated odds ratio for those from the intermediate occupational class compared to the professional occupational social class (the reference group) is given by $\hat{\lambda}=\exp (-0.2339)=0.79$. The association between the two highest occupational social classes and studying for a degree has been reduced (by which we mean that the odds are closer to 1, which represents no association) by the inclusion of the other variables; the odds ratio has increased from 0.53 to 0.79 . This is consistent with what we might expect, having extended the analysis to include additional explanatory variables. Unfortunately, the comparison of the two odds ratios does not give us any meaningful measure of how 


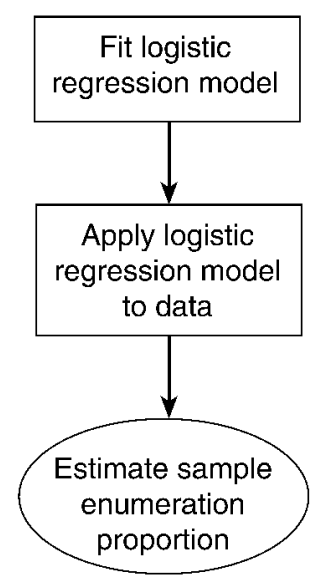

FIG. 1.

much the association has been reduced. As explained above, we would expect the odds ratio to change with the inclusion of explanatory variables even if they were uncorrelated with occupational social class. Sample enumeration provides a method of estimating the contribution of control variables towards 'explaining' the observed responses using a readily understood metric. The method of sample enumeration proceeds from fitting a logistic regression model and has the unique advantage of allowing us to quantify the individual 'substantive' significance of explanatory variables.

In essence, sample enumeration is a model interpretation procedure. The fitted (estimated) model is applied to the sample in order to estimate the relationship between explanatory variables and the response variable over the population under study. The practical process is depicted in Fig. 1. We have a set of data that provides us with the observed proportions of young people studying for a degree from different occupational social class backgrounds. To provide increased statistical control we have fitted a logistic regression model to our data that includes a series of other significant explanatory variables. Our interest is in the effects of occupational social class on participation in degree level higher education. And, specifically, we would like to quantify the effects of occupational social class. Using sample enumeration, we address this challenge by asking the question 'what proportion of young people in the intermediate occupational social class would have been studying for a degree if they had been in the professional occupational social class, all other things being equal?'

The process of sample enumeration is best understood by the following analogy. Sample enumeration is simply a technical process by which we can, hypothetically, promote all of the young people in the intermediate occupational social class to the professional occupational social class. Using our logistic regression model we can then estimate the proportion of these young people who would have been studying for a degree given their other characteristics (measured by the other explanatory variables).

Our observed percentages of young people from the professional occupational social class and from the intermediate occupational social class studying for a degree are $33 \%$ (240/720) and $21 \%(577 / 2747)$ respectively (see Table V). The practical process of employing sample enumeration methods is relatively straightforward. The young people from the intermediate occupational social class were extracted from the sample. The fitted logistic regression model was then applied to each young person from the intermediate occupational social class, but the class effect was set to zero. This is 
TABLE VI. Sample enumeration results—studying for a degree logistic regression

\begin{tabular}{|c|c|c|c|c|c|}
\hline & \multirow[b]{2}{*}{$\begin{array}{l}\text { Observed } \\
\text { rate }\end{array}$} & \multirow[b]{2}{*}{$\begin{array}{l}\text { Estimated } \\
\text { rate through } \\
\text { sample } \\
\text { enumeration }\end{array}$} & \multirow[b]{2}{*}{$\begin{array}{l}\text { Observed } \\
\text { difference }\end{array}$} & \multicolumn{2}{|c|}{ Estimated shortfall } \\
\hline & & & & $\begin{array}{l}\text { Due to } \\
\text { effect }\end{array}$ & $\begin{array}{l}\text { Due to } \\
\text { other } \\
\text { variables } \\
\text { in the } \\
\text { model }\end{array}$ \\
\hline Professional & $33 \%$ & - & - & - & - \\
\hline Intermediate & $21 \%$ & $24 \%$ & $12 \%$ & $3 \%$ & $9 \%$ \\
\hline Skilled non manual & $12 \%$ & $16 \%$ & $21 \%$ & $4 \%$ & $17 \%$ \\
\hline Skilled manual & $7 \%$ & $10 \%$ & $26 \%$ & $3 \%$ & $23 \%$ \\
\hline Semi-skilled & $5 \%$ & $8 \%$ & $28 \%$ & $3 \%$ & $25 \%$ \\
\hline Unskilled & $2 \%$ & $4 \%$ & $31 \%$ & $2 \%$ & $29 \%$ \\
\hline Males & $17 \%$ & & & & \\
\hline Females & $13 \%$ & $16 \%$ & $4 \%$ & $3 \%$ & $1 \%$ \\
\hline Indian origin & $26 \%$ & & & & \\
\hline Not of Indian origin & $15 \%$ & $23 \%$ & $11 \%$ & $8 \%$ & $3 \%$ \\
\hline Graduate parents & $30 \%$ & & & & \\
\hline $\begin{array}{l}\text { Non-graduate } \\
\text { parents }\end{array}$ & $12 \%$ & $16 \%$ & $18 \%$ & $4 \%$ & $14 \%$ \\
\hline Independent school & $43 \%$ & & & & \\
\hline $\begin{array}{l}\text { Attended state } \\
\text { school }\end{array}$ & $13 \%$ & $18 \%$ & $30 \%$ & $5 \%$ & $25 \%$ \\
\hline Parents own home & $17 \%$ & & & & \\
\hline $\begin{array}{l}\text { Parents don't } \\
\text { own home }\end{array}$ & $5 \%$ & $7 \%$ & $12 \%$ & $2 \%$ & $10 \%$ \\
\hline Not married (aged 19) & $15 \%$ & & & & \\
\hline Married & $2 \%$ & $5 \%$ & $13 \%$ & $3 \%$ & $10 \%$ \\
\hline
\end{tabular}

analogous to promoting each young person in the intermediate social class to the professional occupational social class. This allows us to estimate the probability of each of these young people studying for a degree if they behaved like their counterparts in the professional occupational social class whilst controlling for other variables in the model. Summing these probabilities allows us to construct expected frequencies having eliminated the direct consequences of occupational social class.

The results are reported in Table VI. They show that, whereas only $21 \%$ of those in the intermediate social class were studying for a degree, the sample enumeration proportion increases to $24 \%$. This directly answers the question, 'what proportion of young people in the intermediate occupational social class would have been studying for a degree if they had been in the professional occupational social class, all other things being equal?' The sample enumeration method has isolated the direct effect of occupational social class as $3 \%$ in this case.

The observed or 'original' difference between the rates of young people studying for a degree in the professional occupational social class and in the intermediate social class was $12 \%(33 \%-21 \%)$. This figure is the observed difference or 'shortfall' between the rates of young people studying for a degree in these two occupational social classes. Through sample enumeration we are able to report that $3 \%$ of the original $12 \%$ shortfall is due to the effect of occupational social class. And we can therefore conclude that $9 \%$ of the original shortfall is due to the combined effects of the other explanatory variables. These figures provide a means of quantifying the 'substantive' importance of 
the effect of occupational social class in a form that we would argue is easily communicated and understood.

\section{DISCUSSION}

\section{Social Class}

An important finding is that, after educational attainment has been controlled for, the occupational social class of a young person's family is highly statistically significant. The observed shortfall increases as we move down the occupational social class groups. The sample enumeration methodology indicates that the estimated shortfall due to the class effect for each of the social classes remains around 3\%. Overall, these findings remain consistent with the theoretical claim that young people from less advantaged social backgrounds are less likely to enter higher education and study degree level courses. Through sample enumeration we can report that when measured by parental occupational status only, social class accounts for just a small proportion of the difference in the participation rates in degree level education. This is an important finding as it warns against an account of the effects of social class upon filial participation in degree level education that uncritically relies upon parental occupational status as the sole measure of social class.

\section{Gender Effects}

A further important finding, given the government's concerns about access and equality of opportunity, is that young women in this cohort were less likely to enter higher education than their male counterparts. The observed rate of participation by young men was $17 \%$ compared to the $13 \%$ entry rate for young women. Through sample enumeration the estimated rate of female participation was $16 \%$, an increase of $3 \%$. Again, this is analogous to moving the young women into the male category and then examining the combined effects of the other explanatory variables.

This observed difference in entry rates between young men and women was $4 \%$. Therefore the estimated shortfall due to the gender effect was $3 \%$ and the combined effect of the other variables was $1 \%$. This is an important finding in terms of policy formulation because the difference between males and females can mostly be attributed to the gender effect. This indicates that, largely, the difference in participation rates could plausibly be attributed to gender discrimination. However, our results are uninformative as to the nature and the process by which discrimination may operate. Having only analysed data from a single cohort of young people, at the present time, we cannot be sure how universal the gender effect finding is.

\section{Ethnicity Effects}

The point that must be stressed is that in our analysis ethnicity, per se, is not statistically significant. Taken on its own this can be misleading as various ethnic groups have differential rates of participations in higher education. Expressed descriptively, young people of Indian origin have the highest rates of participation with approximately a quarter studying for a degree. The next highest rate was young people of Pakistani origin, closely followed by White young people. About $14 \%$ of young people from these ethnic backgrounds were studying for a degree. Less than $10 \%$ of Bangladeshi and 
Black, African or Afro-Caribbean young people were studying for a degree. The government is already aware of these differences and in particular the lower rates of participation by Bangladeshis and Afro Caribbeans [1].

The most obvious substantive point that we wish to highlight is that any analysis that combines young people of Asian origin (i.e. those of Indian, Pakistani and Bangladeshi origin) is likely to lead to misleading conclusions. The next caveat that we must issue is that there were small numbers of young people in some of these ethnic groups. The fact that young people of Indian origin are more successful in terms of rates of participation in higher education goes against simple arguments that are premised upon the existence of discrimination within the education system. Whilst we do not wish to discount the effects of discrimination tout court we wish to warn against simplistic claims.

The observed rate of young people of Indian origin entering higher education is $26 \%$ compared to a rate of only $15 \%$ for young people of non-Indian origin (Table VI). The sample enumeration methodology estimates that $23 \%$ of non-Indian young people would attend higher education if they behaved like their counterparts of Indian origin. This represents an increased rate of $8 \%$. The observed shortfall between these groups was $11 \%$. We can conclude that $8 \%$ of the observed shortfall is due to the ethnicity effect and $3 \%$ is due to the combined effect of the other explanatory variables. Sample enumeration indicates that the majority of the difference in the entry rates to higher education for these two groups is accounted for by the ethnicity variable. Sociologically, this is an important finding since the difference between young people of Indian origin and other young people is largely associated with their ethnicity. Sociologically what is required, therefore, is a more comprehensive and subtle investigation of the relevance of this difference.

A point of caution must be raised at this point, however. Our analysis uses a measure from the YCS that combines all young people of Indian origin. This combines Hindus, Muslims and Sikhs as well as young people from East Africa who might also consider themselves as being of Indian origin. It is plausible to assume that these sub-groups might be distinctively different in terms of their educational progress. A further caveat is that the measure contained within the YCS also does not distinguish young people born in Britain from those born overseas. Again, this presents a problem as we might plausibly expect that native and non-native English speakers would have different educational experiences.

\section{Parental Education and Independent Schooling}

There is a substantively interesting relationship between parental education and attendance at an Independent school [2]. Examining the parameter estimates (see Table VII) we can conclude that for a young person who attends an Independent school having non-graduate parents does not have a large effect on the likelihood that they will be

TABLE VII. Parental education by school attendance (odds ratios)

\begin{tabular}{lcc}
\hline & Attended independent school & Attended state school \\
\hline Graduate parents & 1 & 0.78 \\
Non-graduate parents & 0.93 & 0.44 \\
\hline
\end{tabular}


studying for a degree. Similarly, attending a state school does not appear to have a large effect on the likelihood of a young person with graduate parents studying for a degree. Young people who attended state schools and did not have graduate parents had the lowest likelihood of studying for a degree.

Conceptually, these results can be considered another way. Attending an Independent school increases a young person's likelihood of studying for a degree. At the same time, having graduate parents increases a young person's likelihood of studying for a degree. The increased likelihood of studying for a degree for those young people who have graduate parents and attended an Independent school is not equivalent to the sum of the individual positive effects of these two factors. Given the magnitude of these effects an interesting question is posed with regard to the value of Independent education for young people with graduate parents.

Once again, through sample enumeration we are able to quantify the effects of individual explanatory factors. At first sight the strength of the parental education and Independent schooling factors appears to be large (see Table IV). The figures reported in Table VI indicate that both parental education and the school effect account for a small amount of the observed shortfalls in the entry rates to higher education.

Whilst young people with graduate parents are socially advantaged (a higher proportion were studying for a degree) this effect was smaller than we initially assumed. Similarly, young people who attended Independent schools have increased social advantage, and therefore a higher entry rates into higher education, but again this effect is smaller than we initially assumed.

We have highlighted the inter-related nature of schooling and parental education and our conclusion is that any substantive interpretation must be aware of the significant interaction between these factors. This government and their predecessors have both expressed concerns about educational standards and school effectiveness [3]. Our findings highlight the dangers of any simplistic analysis of the effects of schooling upon entry to higher education that does not take account of parental education.

\section{Other Factors}

Increased family size is also important. All other things being equal, young people from larger families have a lower chance of studying for a degree. Turning our attention to home ownership, $17 \%$ of young people whose parents owned their own home were studying for a degree, in contrast to only $5 \%$ of young people whose parents were not homeowners. The sample enumeration methodology estimated a participation rate of $7 \%$ for those young people whose parents were not homeowners. This increase of $2 \%$ illustrates the small effect of home ownership. Whilst home ownership is not a direct indicator of social background it does, however, represent increased family wealth and improved material conditions.

Within the sociology of youth there is much concern about young people's lifestyles and transitions from youth to more permanent modes of adult status (see McDonald et al., 1993; Irwin, 1995; Gayle, 1998). The analysis of marital status reports low levels of participation in degree level education by those who marry early. This is an important finding as it emphasises that young people who marry early tend to opt out of continuing into higher education. However, through sample enumeration we can conclude that this is a small effect. Any comprehensive understanding of the effect of early marriage on entry into higher education must be cognisant of the fact that only a small proportion of the difference in entry rates can be explained by early marriage. 


\section{CONCLUSION}

\section{Substantive Conclusion}

The central message of this paper is that there is a need for comprehensive and systematic analysis of the factors that influence young people's entry into higher education and participation in degree level courses if the government is to develop 'evidence based' policy initiatives.

Halsey (1993) argues that class, gender and ethnicity are now the three giants in the path of aspirations toward equality of access to higher education. Overall, our results have emphasised that class, gender and ethnicity are important but there are a complex and inter-related set of factors that influence young people's entry into higher education. The answer to our primary research question namely, 'net of attainment, do external influences such as family's social class, parental education, gender and ethnicity influence a young persons chance of studying for a degree?' is unequivocally 'yes'. However, the 'direct' effects of many of these factors are less important than we initially assumed.

The government have stated that their priority is to reach out to groups that are under-represented in higher education. This includes young people from families with semi-skilled and unskilled occupational backgrounds. Our analysis has reported that the differences in participation in degree level education by young people from these social groups are only partially explained by their parent's occupational class status. The corollary of this being that policy initiatives aimed at combating the differential levels of entry into higher education will have to embrace a more comprehensive conception of differences than is afforded by more restrictive occupational social class analysis.

In the analysis above, we have reported a significant gender effect. British higher education can boast a minor success in terms of increasing women's access to higher education. Women now account for over $50 \%$ of the students in higher education but the government is aware of the gender imbalance across subject disciplines [4]. The aggregate figures might occlude the picture for young women as they include mature female students, so we counsel against complacency on this important issue.

The complexity of examining the effects of ethnicity has been raised in this analysis. The effects of ethnicity per se are not dramatic and do not capture the differences in participation rates across ethnic groups. Policy initiatives designed to increase participation by certain ethnic groups will have to be sensitive to the more subtle nuances of the effects of ethnicity.

We have also pointed to some of the issues associated with the measurement of ethnicity and the shortcomings of existing measures. These issues are well known and, presently, much sociological analysis in bedevilled by these problems. Prudent government policy will be sensitive to the limitation of social research in this area.

The effect of parental education on filial entry to higher education is inter-woven with the effects of schooling. These findings are consistent with the theoretical claim that increased parental education and independent schooling both provide greater levels of social advantage. On our evidence, it is probable that the offspring of the current bulge in student numbers may also have a high likelihood of entering higher education. In view of this, forecasting the future demand for higher education will present a challenging set of problems for planners.

The late 1980 s and early 1990 s saw a huge expansion in the number of mature students. Presently, increasing numbers of people are entering higher education later and mature students make up a large proportion of full-time degree students (HEFCE, 
1996). In light of our analysis it is plausible to assume that the offspring of these mature students are also more likely to want to enter higher education than they might have been had their parents not become graduates. In terms of planning for future demand this presents a vexing, and more immediate problem.

\section{Methodological Conclusion}

We are keen to point out that these results are derived from cross-sectional analysis and therefore are relatively uninformative about social processes [5]. In future analysis we are keen to exploit the longitudinal nature of the YCS data in an attempt to uncover the processes underpinning young people's entry into higher education. At this stage we have been able to emphasise the importance of a number of factors but we are not in a secure position to draw conclusions about the temporal stability of these effects. The obvious solution to this is to pool cohorts of data from the YCS in order to compare the behaviour of young people over time.

The analysis that we have presented offers a clear example of the benefits of sample enumeration for the interpretation of logistic regression models. Goldstein (1993) concludes that one of the useful things about statistical models of educational realities is that, so long as the assumptions are clearly and correctly stated, one can obtain reliable conclusions that in their own terms are beyond reproach. He further states that what makes things difficult is that trying to communicate results within the social science community is fraught with difficulties even when the attempt is genuinely one of honest communication.

An overall attraction of sample enumeration methods is that by quantifying effects directly, and in a tractable fashion, researchers are able to assess the 'substantive' rather than the 'statistical' importance of explanatory variables. Sample enumeration methods also provide a means of reporting the effects of individual explanatory variables in a manner that is communicable to researchers whose interests are primarily substantive rather than methodological. A further benefit is that results are also easily communicated to non-academic audiences with no experience of interpreting the results from statistical models. Sample enumeration methods also provide a mechanism for comparing the effects of variables in different (i.e. non-nested) logistic regression models. Extensions of the method to the interpretation of longitudinal data are also feasible (Davies, 1992).

\section{ACKNOWLEDGEMENTS}

This work was undertaken as part of an Economic and Social Research Council, Analysis of Large and Complex Datasets, Phase II Visiting Fellowship Award (H519 44 5002 97). The Economic and Social Research Council Data Archive supplied the data. We would like to thank Professor D. Timms and Dr H. Buchanan-Smith for their comments on early drafts.

\section{NOTES}

[1] See Chapter 4 Section 5 (Higher Education and the Dearing Report) of the Green Paper.

[2] We are aware that complex interaction effects are sometimes difficult to replicate in other datasets. We have undertaken some exploratory analysis of data from 
Cohort 6 of the YCS (i.e. young people born five years later). When we fitted the model reported in Table IV to the data from Cohort 6 the type of school and parental education interaction effect was still significant, which indicates that this finding is reasonably robust.

[3] This has led to a wealth of academic interest and critique (for a flavour of this debate see Aitken \& Longford, 1986; Goldstein \& Spiegelhalter, 1996; Goldstein \& Sammons, 1997).

[4] See especially the Higher Education Appendix Section 1 of the Green Paper.

[5] See Davies (1994).

\section{REFERENCES}

Aitken, M. \& Longford, N. (1986) Statistical modelling issues in school effectiveness studies, Fournal of the Royal Statistical Society A, 149, pp. 1-43.

BATEy, P. \& Brown, P. (1997) The Influence of Neighbourhood Type on Participation in Higher Education (Bristol, Higher Education Funding Council for England).

Blackburn, R. \& JaRman, J. (1993) Changing inequalities in access to British universities, Oxford Review of Education, 19, pp. 197-216.

BREEN, R. \& GoldThorPe, J. H. (1997) Explaining educational differentials-towards a formal rational action theory, Rationality and Society, 9, pp. 275-305.

Bourdieu, P. (1986) Distinction: A social critique of the judgement of taste (London, Routledge).

Burnhill, P., Garner, C. \& McPherson, A. (1988) Social change, school attainment and entry to higher education 1976-1986. In: D. RAFFE (Ed.) Education and the Youth Labour Market: schooling and scheming (London, Falmer Press).

Burnhill, P., Garner, C. \& MCPherson, A. (1990) Parental education, social class and entry to higher education 1976-86, Fournal of the Royal Statistical Society A, 153, pp. 233-248.

Cheng, Y. \& HeAth, A. (1993) Ethnic origins and class destinations, Oxford Review of Education, 19, pp. 151-166.

DAviES, R.B. (1992) Sample enumeration methods for model interpretation. In: van der Heijden, P., Jansen, W., Francis, B. \& Seeber, G. (Eds) Statistical Modelling: a selection of papers from the Sixth International Workshop (Netherlands, Elsevier Science Publishers).

DAviEs, R.B. (1994) From cross-sectional to longitudinal analysis. In: DALE, A. \& Davies, R.B. Analyzing Social and Political Change: A casebook of methods (London, Sage).

DeArIng, R. (1997) Higher Education in the Learning Society. Report of The National Committee of Inquiry into Higher Education (London, Her Majesty's Stationery Office).

Drew, D., Gray, J. \& Sime, N. (1992) Against the odds: the education and labour market experiences of black young people, Youth Cohort Series, 19.

Egerton, M. \& Halsey, A.H. (1993) Trends by social class and gender in access to higher education in Britain, Oxford Review of Education, 19, pp. 183-196.

ERIKSON, R. (1984) Social class of men, women and families, Sociology, 18, pp. $500-514$.

GAYLE, V. (1998) Structural and cultural approaches to youth: structuration theory and bridging the gap, Youth E Policy, 61, pp. 59-72. 
Goldstein, H. (1993) Assessing group differences, Oxford Review of Education, 19, pp. $141-150$.

Goldstein, H. \& Sammons, P. (1997) The effectiveness of secondary and junior schools on sixteen year examination performance: a cross-classified multi-level analysis, School Effectiveness and School Improvement, 8, pp. 219-230.

Goldstein, H. \& Spiegelhalter, D. (1996) League tables and their limitations: statistical issues in comparisons of institutional performance (with discussion), Fournal of the Royal Statistical Society A, 159, pp. 385-444.

HALSEY, A.H. (1993) Trends in access and equity in higher education: Britain in international perspective, Oxford Review of Education, 19, pp. 129-140.

Halsey, A.H., Heath, A. \& Ridge, J. (1980) Origins and Destinations (Oxford, Clarendon Press).

Higher Education Funding Council for England (1996) Widening Access to Higher Education: A Report by the Advisory Group on Access and Participation (Bristol, Higher Education Funding Council for England).

IRWIN, S. (1995) Rights of Passage: social change and the transformation from youth to adulthood (London, University College London Press).

MacDonald, R. Banks, S. \& Hollands, R. (1993) Youth and policy in the 1990s, Youth E Policy, 40, pp. 1-9.

Marshall, G., Rose, D., Newby, H. \& Vogler, C. (1988) Social Class in Modern Britain (London, Unwin Hyman).

Metcalf, H. (1997) Class and Higher Education: participation of young people from lower social classes (London, The Council for Industry and Higher Education).

Modood, T. (1993) The number of ethnic minority students in British higher education: some grounds for optimism, Oxford Review of Education, 19, pp. 167-182.

Moore, P. (1983) Higher education: the next decade, fournal of the Royal Statistical Society $A, 146$, pp. 213-345.

PARRY, G. (1997) Patterns of participation in higher education in England: a statistical summary and commentary, Higher Education Quarterly, 51, pp. 6-28.

Paterson, L. (1993) Regionalism among entrants to higher education from Scottish schools, Oxford Review of Education, 19, pp. 231-256.

PATERSON, L. (1997) Trends in higher education participation in Scotland, Higher Education Quarterly, 51, pp. 29-48.

Payne, C., Payne, J. \& Heath, A. (1994) Modelling trends in multi-way tables. In: Dale, A. \& Davies, R.B. (Eds) Analyzing Social \& Political Change (London, Sage).

RAAB, G. (1998) Participation in Higher Education in Scotland (Edinburgh, Napier University).

Royal Statistical Society (1985) Projections of student number in higher education, Fournal of the Royal Statistical Society A, 148, pp. 175-213.

Redpath, B. \& Harvey, B. (1987) Young People's Intentions To Enter Higher Education (London, Office of Population Census and Survey).

RudD, E. (1976) What a falling birthrate will mean to universities in 1982, Times Higher Education Supplement, 265, p. 10.

RudD, E. (1987a) The educational qualifications and social class of the parents of undergraduates entering British universities in 1984, Fournal of the Royal Statistical Society $A, 150$, pp. 346-372.

RudD, E. (1987b) Students and social class, Studies in Higher Education, 12, pp. 99-106. 
Savage, M. \& Egerton, M. (1997) Social mobility, individual ability and the inheritance of class inequality, Sociology, 31, pp. 645-672.

Correspondence: Vernon Gayle, Department of Applied Social Science, Stirling University, Stirling FK9 4LA, UK 
Copyright of Oxford Review of Education is the property of Carfax Publishing Company and its content may not be copied or emailed to multiple sites or posted to a listserv without the copyright holder's express written permission. However, users may print, download, or email articles for individual use. 